\title{
Strength characteristics of reinforcement material used in deformed geotextile reinforced soil wall
}

\author{
Hirotake Nakamura $^{\text {i) }}$, Seiya Yokota ${ }^{\text {ii) }}$, Shinichiro Tsuji ${ }^{\text {iii) }}$ and Naoki Tatta ${ }^{\text {iv) }}$
}

i) Engineer, Central Nippon Expressway Co., Ltd.Kanazawa Branch, 170, Higashi, Kamino-machi, Kanazawa-shi, Ishikawa, japan

ii) Manager, Road Research Department, Nippon Expressway Research Institute Co., Ltd., 1-4-1 Tadao, Machida-shi, Tokyo, Japan

iii) Engineer, Sales promotion department, Maeda Kosen Co., Ltd., 38-3 Haruemachio Okinunome, Sakai-shi, Fukui, Japan.

iv) Manager, Sales promotion department, Maeda Kosen Co., Ltd., 38-3 Haruemachio Okinunome, Sakai-shi, Fukui, Japan.

\begin{abstract}
Nowadays, geotextile reinforced soil walls are being used more often, and with that, the number of reports on the deformation of these soil walls is on the rise. But we do not yet fully understand what happens to the reinforcement material within the embankment when deformation occurs. To find out, the authors have studied density, water content ratio, velocity of elastic wave, and strength of reinforcement material of the deformed embankment interior, where the mudstone reinforcement wall was rebuilt after it had been damaged. Studies showed that penetrating groundwater and rain had weakened the mudstone used to construct the embankment, causing deformation. We also confirmed that some parts of the reinforcement material were much fragile and showed considerably lower deformation capacity compared with the new reinforcement material. These findings indicate the possibility of lowered strength and deformation capacity of reinforcement material within the damaged geotextile reinforcement soil wall.
\end{abstract}

Keywords: geotextile, reinforced soil wall, mudstone

\section{INTRODUCTION}

About half of the $1,000,000 \mathrm{~m}^{2}$ of reinforcement soil walls constructed on Japanese expressway are geotextile reinforced soil walls.

This paper reports on a study conducted on the deformation of a geotextile reinforced soil wall using mudstone as banking material. During reconstruction, density, water content, velocity of elastic wave, and strength of reinforcement material inside the embankment were studied. Nakamura et al.(2013) found that groundwater and rain had weakened the mudstone, causing the area near the wall-face to $\operatorname{sink}^{1) \text {, }}$ and that geotextile in places where deformation was large was more fragile and particularly weak to deformation.

\section{STRUCTURE AND DEFORMATION OF REINFORCED SOIL WALL}

\subsection{Structure}

The studied wall extends $160 \mathrm{~m}$, and has an area of about $1,200 \mathrm{~m}^{2}$. Two walls, one $10 \mathrm{~m}$ high and another $15 \mathrm{~m}$ high are built in succession at two swamp areas. The core of the geotextile is aramid fiber covered with high density polyethylene. The wall cross-section and layout of reinforcement material are shown in Fig. 1. At $15 \mathrm{~m}$ high, a material with quality control strength of
$80-150 \mathrm{kN} / \mathrm{m}$ is used. Cut soil from the surrounding area is used as banking material. The soil is mudstone of the Neogene Period and is easy to slake.

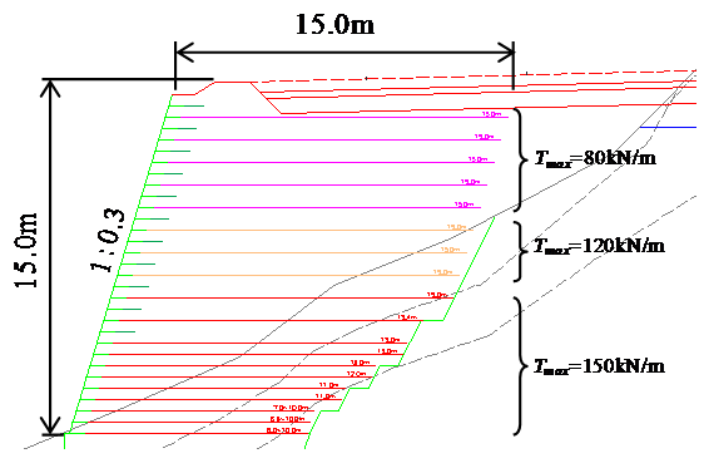

Fig. 1. Wall cross-section and reinforcement material layout.

NEXCO's Design Standards (Central Nippon Expressway Co., Ltd.,2012) and Geotextile Manual (Public Works Research Center.,2000) were used to design the wall. Soil modulus of banking material used in designing the wall were: adhesive force $C=60.6\left(\mathrm{kN} / \mathrm{m}^{2}\right)$, angle of shearing resistance $\Phi$ $=18.6\left(^{\circ}\right)$, unit weight $\gamma=19\left(\mathrm{kN} / \mathrm{m}^{3}\right)$. To study internal stability $C=10\left(\mathrm{kN} / \mathrm{m}^{2}\right)$ was used. Design horizontal seismic coefficient 0.16 was used for earthquake related design. 


\subsection{Deformation}

Deformation began about a year after the wall's completion. Cracks had developed (Fig. 2) and were located above the geotextile, extending the length of the wall; some were about $15 \mathrm{~cm}$ wide and $40 \mathrm{~cm}$ deep. The displacement of the wall where the wall is $10 \mathrm{~m}$ high was as follows: sinkage at upper front-face, $318 \mathrm{~mm}$; horizontal displacement, $406 \mathrm{~mm}$. At height $15 \mathrm{~m}$, the sinkage was $406 \mathrm{~mm}$ and horizontal displacement $521 \mathrm{~mm}$.

Physical properties of the banking soil is as follows: gritty fine-grain sand, natural water content $w_{\mathrm{n}}=14.4 \%$, grain sizes are gravel fraction $67.8 \%$, sand fraction $15.1 \%$, fine particle fraction $17.1 \%$. Crush rate of rock was $72.6 \%$ and slaking rate was $100 \%$ (Central Nippon Expressway Co., Ltd.,2012). Maximum dry density for ramming test was $\rho \mathrm{dmax}=1.789\left(\mathrm{~g} / \mathrm{cm}^{3}\right)$, while the optimum water content ratio was $w_{\mathrm{opt}}=15.4 \%$. A $10 \mathrm{t}$ class vibrating roller was used to make finished thickness of one layer $30 \mathrm{~cm}$, and the number of rolling compaction was 8 . Density of $92 \%$ or more compared with the maximum dry density rate of $1.819\left(\mathrm{~g} / \mathrm{cm}^{3}\right)$, calculated from on-site rolling tests, was set as the quality control criterion.

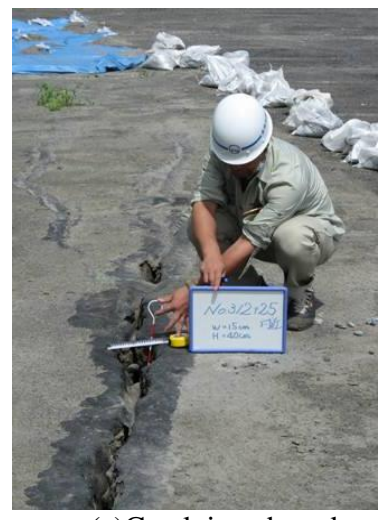

(a)Crack in subgrade

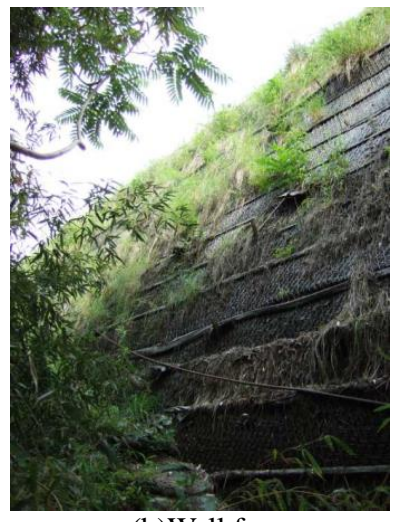

(b)Wall face
Fig. 2. Deformed reinforced soil wall.

\section{STUDY OF REINFORCED SOIL WALL INTERIOR}

Surface wave survey to check the condition of the wall interior was carried out. The two walls were each surveyed in the transverse direction at their maximum heights using a multi-channel, $4.5 \mathrm{~Hz}$ speed-type geophone with vertical directivity. Excitation was at every $2 \mathrm{~m}$. Fig. 3 shows the S-wave speed distribution contour. The dark green part is speed range of about $240(\mathrm{~m} / \mathrm{s})$. Most of this area corresponds to the bedrock area. The upper part $(10 \mathrm{~m}$ to $15 \mathrm{~m})$ is in the low-speed area between 100 and $180(\mathrm{~m} / \mathrm{s})$. The middle to lower part (to about $10 \mathrm{~m}$ ), can be classified as healthy. The lower part, especially up to $4 \mathrm{~m}$ in height, is in the same speed range as the bedrock. The speed distribution was compared with the on-site density and water content tests. The water content was about $20 \%$ to $30 \%$ at the upper front-face and between $13 \%$ and $17 \%$ in the middle to lower area. The water content was high in areas where the speed was low and low in areas where the speed was high. Soil survey showed natural water content $w_{\mathrm{n}}=14.4 \%$. At construction, the water content was about $10 \%$ to $15 \%$, meaning the water content of the upper front-face had risen about $5 \%$. The dry density at the upper front-face was about $1.6\left(\mathrm{~g} / \mathrm{cm}^{3}\right)$, and was $1.8-1.9\left(\mathrm{~g} / \mathrm{cm}^{3}\right)$ at the middle and lower part. When the speed was low, the dry density was low and in areas when the speed was high the dry density was also high.

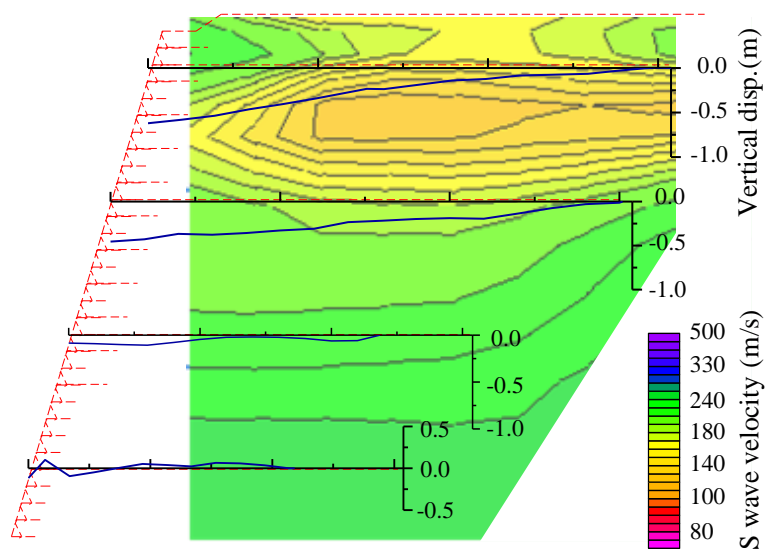

Fig. 3. Wall cross-section and reinforcement material layout.

Fig. 3 also shows the laying height at reconstruction, measured at $1 \mathrm{~m}, 4 \mathrm{~m}, 10 \mathrm{~m}$, and $14 \mathrm{~m}$. The laying height of reinforcement shows the relative difference, using the bedrock area edge as criterion. Reinforcement is laid at almost level, so we can assume that the difference developed after the wall was completed. Measurements revealed that the upper part of the wall had sunk a maximum of $62 \mathrm{~cm}$. The sinking of the reinforcement could be seen throughout the wall, but the depression was large in the upper part and small in the lower part. Areas where the sinking was large corresponded with the low S-wave speed area.

Findings show that the reinforcement wall interior can be classified into two areas: upper and front face area with low rigidity, and middle and lower area with high rigidity.

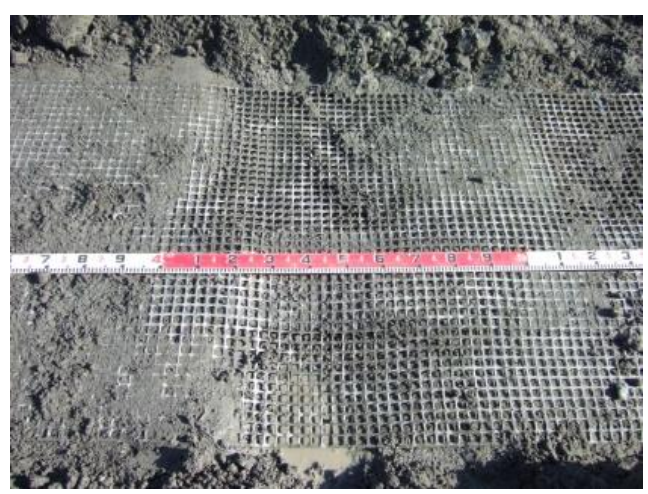

Fig. 4. Removed geotextile. 


\section{REINFROCEMENT MATERIAL HEALTH TEST}

\subsection{Visual Inspection}

We visually inspected and then cut the deformed geotextile into parts to conduct tensile tests (Fig.4). The material is $15 \mathrm{~m}$ by $12 \mathrm{~m}$ and was laid $14 \mathrm{~m}$ high. Its quality control strength is $80(\mathrm{kN} / \mathrm{m})$. At left of the photo is the wall and the material was laid at about $4 \mathrm{~m}$ to $5 \mathrm{~m}$ from the wall face. No big holes or stretching out was confirmed visually and some mudstone around the geotextile had turned into clay.

\subsection{Tensile Test}

The geotextile samples taken from all four layers, described in Fig. 3, were cut into 4 or 5 blocks in the length direction, divided into 12 parts in the width direction, and tested to compare their current tensile strength with that at production. Two of the three strands of the pieces were cut off and the test was done on the one remaining strand. The tests were conducted under the test conditions to check quality at production. The tension strain speed was set at $50 \% / \mathrm{min}$.

Fig. 5 shows the relation between breaking strain and resistance. Sample from nearest to the wall face is marked No.1, and No.5 is closest to the bedrock. Quality control strength at production and the design tensile strength used for designing geotextile, which takes creep into consideration, were used. Fig. 5 (a) shows the test results at laying height of $10 \mathrm{~m}$. The tensile strength of No. 1 and No. 2 lowered a maximum of $20(\mathrm{kN} / \mathrm{m})$ compared with the quality control strength. The breaking strain also lowered about $2 \%$ compared with that at production. On the other hand, No. 3, No. 4 and No. 5's results were the same as that at production. Fig. 5 (b) shows the results at laying height of $1 \mathrm{~m}$. The tensile strength was higher than the quality control value and breaking strain equaled or was higher than that at production. We have confirmed that at this height the condition of the geotextile equals that at production.

Fig. 6 shows the relations between relative sinkage of geotextile edge and the tensile strength ratio within the tested area. When the sinkage is over about $70 \mathrm{~mm}$, the tensile strength of some blocks lowered to below 1.0. When deformation increases, the tensile strength ratio tends to be smaller. This is thought to be cause by slaking causing deformation, leading to excessive tension placed on the geotextile for long periods. But the design tensile strength of the geotextile was maintained. On the other hand, there was no slagging of the geotextile at the lower part of the wall and the S-wave speed was relatively fast. The tensile strength was over 1.0 and we can say that quality at production was maintained.

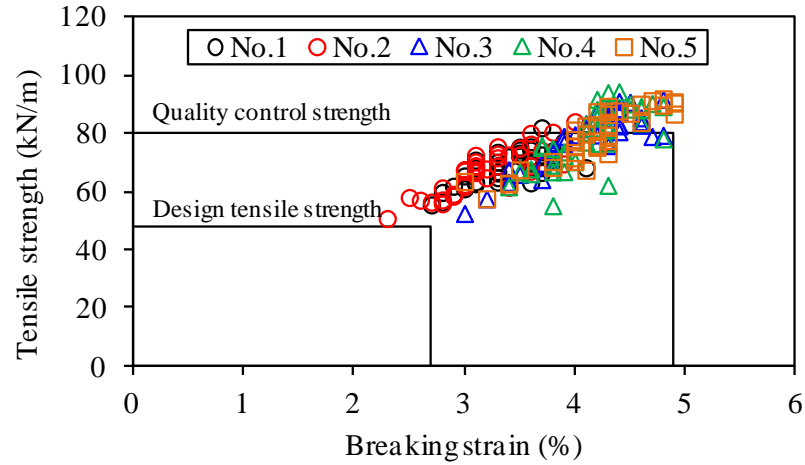

(a)Location2 : at laying height $10 \mathrm{~m}$.

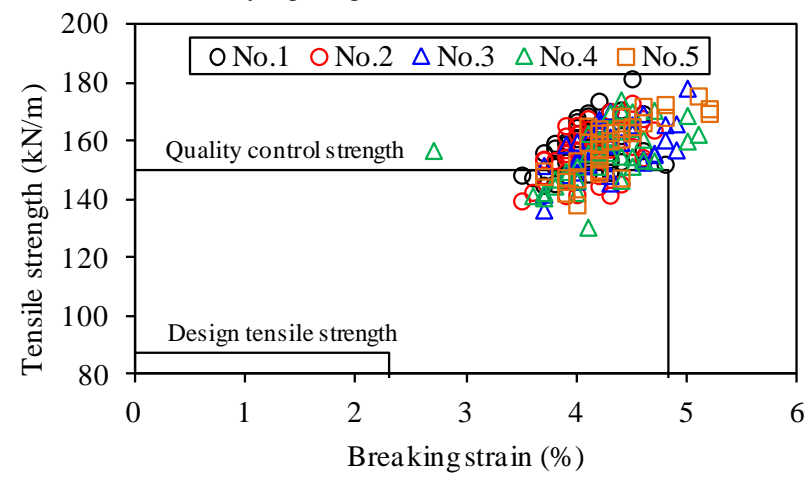

(b)Location 2 : at laying height $1 \mathrm{~m}$.

Fig. 5. Relation between breaking strain and tensile strength.

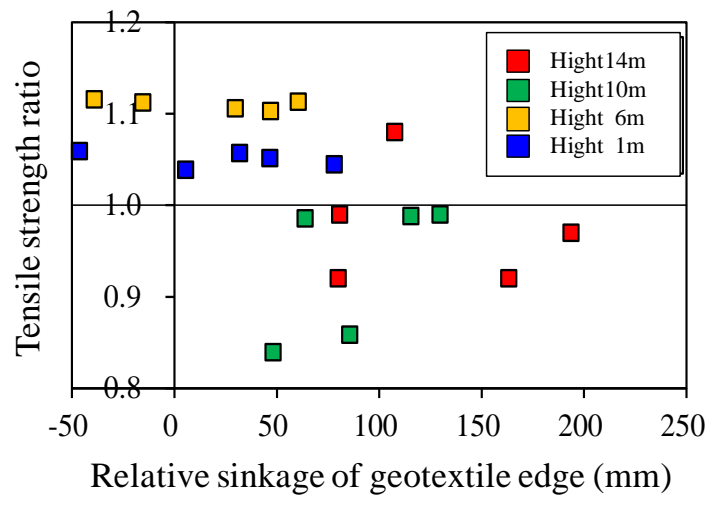

Fig. 6. Relation between relative sinkage of geotextile edge and the tensile strength ratio.

\subsection{Finite element analysis}

A finite element analysis was carried out to estimate the tensile force on geotextile within the embankment. Physical property values used are shown in Table 1. To reproduce the deformation, healthy parts and deformed parts were sorted. As for the elastic modulus, a value estimated from the $\mathrm{N}$ value of the standard penetration test conducted on the healthy part was used for the healthy part. The deformed part was identified as an area 5 meters from the crown of the embankment, where S-wave speed is slow. For this area, the elastic modulus was reduced in accordance with the sinkage of the top of slope. The triaxial compression test results 
were used as the strength invariable for the banking material. A model of the geotextile was made using truss element, which resist only tensile force. The tensile rigidity of each material was used.

The results of the analysis on tensile force acting on the geotextile are shown in Fig. 7. Tensile force of $10-30(\mathrm{kN} / \mathrm{m})$ at the upper part, $60-90(\mathrm{kN} / \mathrm{m})$ in the middle, and $50(\mathrm{kN} / \mathrm{m})$ at the lower part of the wall were generated. And middle to lower part of the wall, where the slip plane is used for the internal stability study, showed the largest tensile force. Fig. 8 is a distribution map of ratios obtained by dividing the tensile force value by the design tensile strength. The laying heights in Fig. 8 are those indicated in Fig. 3.

Table 1. Physical properties for finite element analysis.

\begin{tabular}{c|c|c|c|c|c}
\hline Material & Model & $\begin{array}{c}\mathrm{E} \\
\left(\mathrm{kN} / \mathrm{m}^{2}\right)\end{array}$ & $v$ & $\begin{array}{c}\mathrm{C} \\
\left(\mathrm{kN} / \mathrm{m}^{2}\right)\end{array}$ & $\begin{array}{c}\Phi \\
\left({ }^{\circ}\right)\end{array}$ \\
\hline $\begin{array}{c}\text { Embankment } \\
\text { (Healthy) }\end{array}$ & $\begin{array}{c}\text { Morh- } \\
\text { Coulomb }\end{array}$ & $\begin{array}{c}3.4 \times \\
10^{4}\end{array}$ & 0.3 & 60.6 & 18.5 \\
\hline $\begin{array}{c}\text { Embankment } \\
\text { (Low rigidity) }\end{array}$ & $\begin{array}{c}\text { Morh- } \\
\text { Coulomb }\end{array}$ & $\begin{array}{c}1.0 \times \\
10^{3}\end{array}$ & 0.3 & 0.0 & 18.5 \\
\hline Bedrock & $\begin{array}{c}\text { Linearity } \\
\text { Elasticity }\end{array}$ & $\begin{array}{c}1.0 \times \\
10^{5}\end{array}$ & 0.3 & - & - \\
\hline
\end{tabular}

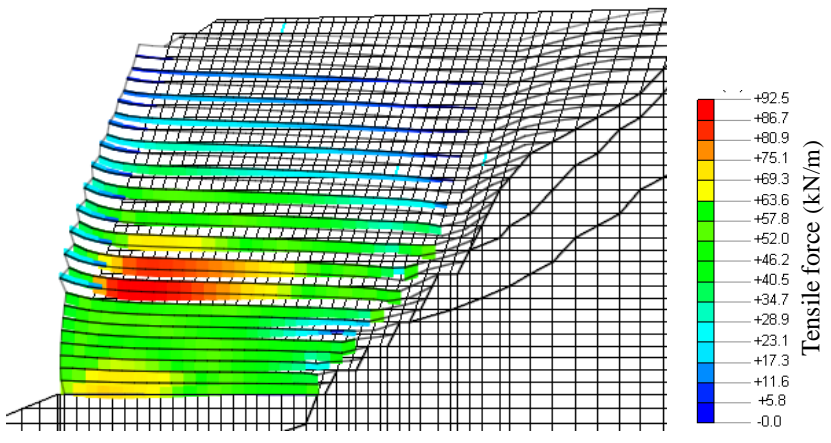

Fig. 7. Tensile force distribution of finite element analysis.

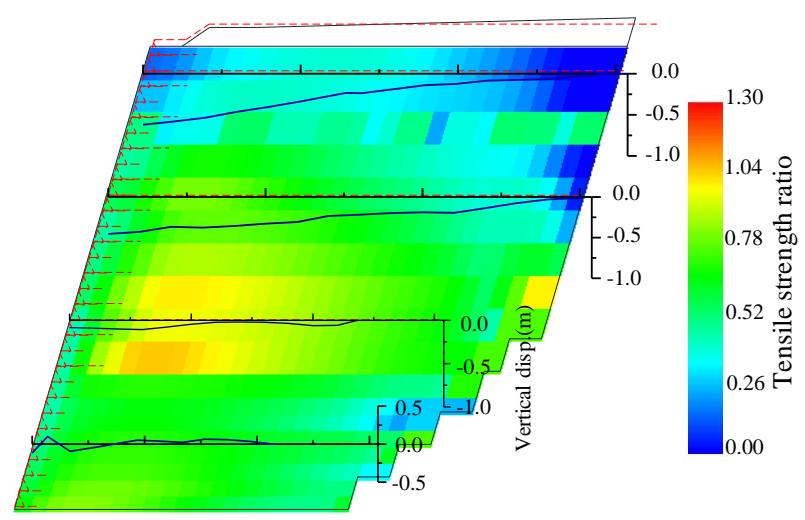

Fig. 8. Ratio between tensile force and design tensile strength.

The numbers are large at the middle to upper and the frontal part of the wall where the slump is large, and tensile force larger than the design tensile strength acted on some parts. This indicates that when slaking lowers embankment rigidity causing deformation, tensile force acting on the geotextile increases and tensile force larger than the design tensile force may be generated. And as the tensile force test results suggest, when a large tensile force is generated, the tensile strength may lower.

Tatsuoka, et al.(2003) have reported that breaking strength of geotextiles is governed by the strain rate, and does not influence the creep load history. Hirai, et al.(2000) have reported that breaking strength of geotextile which was creep-loaded for 1,000 hours is not influenced by creep load history. In these studies, however, the creep load applied was about 0.6 of the breaking strength and the loaded time was also short. Our tests were conducted 6 years after deformation was confirmed, and we found that where the deformation was relatively large, the tensile strength had lowered. We have assumed that this was caused by tensile force which exceeded the design tensile strength acting locally on the geotextile for a long time.

\section{CONCLUSION}

Based on our study of the deformation we have reached the following conclusion.

1) Deformation of reinforced soil wall can be classified into two categories: the deformed part, the upper and frontal part of the wall where rigidity is low and deformation large; and the healthy part, the middle to lower part of the wall where rigidity is high and deformation small.

2) The tensile strength and breaking strain of geotextile were both low at the deformation. But they were equal to those at production in the health parts.

3) When the deformation is particularly great, large tensile strength acts locally on the geotextile, and as a result, the tensile strength and deformation performance of the material may lower greatly.

\section{REFERENCES}

1) Central Nippon Expressway Co., Ltd. (2012): NEXCO Testing Methods Vol.1 Soil Tests (in Japanese).

2) Central Nippon Expressway Co., Ltd. (2012): Standard Design Specifications Vol. 2 Retaining Wall. (in Japanese).

3) Hirai, T. and Yatsu. A. (2000): Evaluation Method about Tensile Strength of Geogrid to use for Dynamic Design, Proc. 15th Geosynthetics Symposium, pp.205-214 (in Japanese).

4) Nakamura, H., Yokota, S., Nakazawa, M., Tatta, N and Tsuji, S. (2013): Case study of deformation geotextile reinforced earth wall using mudstone, Japanese Geotechnical Journal, Vol.8, No.1, 35-51 (in Japanese).

5) Public Works Research Center. (2000): Design and construction manual of geosynthetics reinforced soil (revised version) (in Japanese).

6) Tatsuoka, F., Hirakawa, D., Kongkitkul, W. and Uchimura, T. (2003): On the So-Called Creep Reduction Factor to obtaine Design Tensile Strength of Geosynthetic Reinforcement, Proc. 18th Geosynthetics Symposium, pp.167-174 (in Japanese). 